\title{
Photochemistry of Osmium-Carbyne Complexes
}

\author{
Arnd Vogler*, Josef Kisslinger \\ Institut für Anorganische Chemie, Universität Regensburg, \\ Universitätsstraße 31, D.8400 Regensburg \\ and \\ Warren R. Roper \\ Department of Chemistry, University of Auckland, Auckland, New Zealand \\ Dedicated to Prof. Dr. Dr. h. c. mult. E. O. Fischer, on the occasion of his 65th birthday
}

Z. Naturforsch. 38b, 1506-1509 (1983); received July 5, 1983

Photochemistry, Carbyne Complexes, Osmium Complexes

Upon charge transfer (Os to carbyne) excitation the carbyne complexes

$\mathrm{Os}(\mathrm{CPh})(\mathrm{CO})\left(\mathrm{PPh}_{3}\right)_{2} \mathrm{Cl}$ and $\left[\mathrm{Os}(\mathrm{CPh})(\mathrm{CO})_{2}\left(\mathrm{PPh}_{3}\right)_{2}\right]^{+}$with $\mathrm{Ph}=\mathrm{C}_{6} \mathrm{H}_{5}$ are converted to the carbene complex $\mathrm{Os}(\mathrm{CHPh})(\mathrm{CO})\left(\mathrm{PPh}_{3}\right)_{2} \mathrm{Cl}_{2}$ in solutions containing $\mathrm{HCl}$. It is suggested that the relaxed CT state can be described as square-pyramidal Os(II) complex containing a bent carbyne ligand which carries a lone pair at the coordinating carbon atom. Product formation occurs by the addition of a proton to the carbyne ligand and by attaching a chloride to the osmium completing an octahedral coordination. The cationic carbene complex thus formed is apparently not stable but undergoes a substitution of a CO ligand by chloride.

\section{Introduction}

The first report on carbyne complexes of the type $\mathrm{X}(\mathrm{CO})_{4} \mathrm{M} \equiv \mathrm{C}-\mathrm{R}$ (with $\mathrm{M}=\mathrm{Cr}, \mathrm{Mo}, \mathrm{W}$ and $\mathrm{X}=$ halide) containing a metal-carbon triple bond was published by E. O. Fischer and his group in 1973 [1]. This discovery stimulated a rapid expansion of the chemistry of carbyne complexes $[2,3]$. The synthesis of a large number of these compounds was accompanied by the investigation of their reactivity. This experimental work was followed by theoretical studies of the electronic structure of carbyne complexes [4-7]. While there is an extensive body of observations on thermal reactions the photochemistry of carbyne complexes has been almost unexplored. Although a light-induced reaction of a carbyne complex was reported by $\mathbf{E}$. $O$. Fischer and P. Friedrich, the mechanism of this reaction is not known [8]. This lack of knowledge of the reactivity of carbyne complexes in their electronically excited states prompted our present study as an extension of our work on the photochemistry of a carbene complex [9].

\section{Experimental}

The compounds $\left[\mathrm{Os}(\mathrm{CPh})(\mathrm{CO})_{2}\left(\mathrm{PPh}_{3}\right)_{2}\right] \mathrm{ClO}_{4}$ and $\mathrm{Os}(\mathrm{CPh})(\mathrm{CO})\left(\mathrm{PPh}_{3}\right)_{2} \mathrm{Cl}\left(\mathrm{Ph}=\mathrm{C}_{6} \mathrm{H}_{5}\right)$ were prepared

* Reprints requests to Prof. Dr. A. Vogler. 0340-5087/83/1100-1506/\$01.00/0 according to ref. [10] and [11]. Solvents were of spectro-grade quality and saturated with nitrogen or argon. The solvent mixtures of $\mathrm{CH}_{2} \mathrm{Cl}_{2}, \mathrm{C}_{2} \mathrm{H}_{5} \mathrm{OH}$, and aqueous $\mathrm{HCl}$ were prepared by adding concentrated hydrochloric acid to a large excess of equal volumes of $\mathrm{CH}_{2} \mathrm{Cl}_{2}$ and $\mathrm{C}_{2} \mathrm{H}_{5} \mathrm{OH}$. The overall concentrations of $\mathrm{HCl}$ are specified for every measurement. Solutions of the complexes were prepared under a nitrogen or argon atmosphere using standard procedures for handling air-sensitive compounds.

The light sources were an Osram HBO $100 \mathrm{~W} / 2$ and a Hanovia $\mathrm{Xe} / \mathrm{Hg} 977 \mathrm{~B}-1$ (1000 W) lamp. The Schott cut-off filters WG 305/2 and WG 320/2 were used for irradiations at wavelengths longer than 305 and $320 \mathrm{~nm}$. The Schott interference filters PIL 313, 333 , and 366 were used for the selection of the mercury lines at 313,333 , and $366 \mathrm{~nm}$. The photolyses were performed in 1-cm spectrophotometer cells at room temperature. For quantum-yield determinations the complex concentrations were such as to have essentially complete light absorption. The total amount of photolysis was limited to less than $5 \%$ to avoid light absorption by photoproducts. Absorbed light intensities were determined by a Polytec pyroelectric radiometer which was calibrated and equipped with a detector RkP-345. The experimental error of the quantum yields were $\pm 30 \%$.

Progress of the photolyses were monitored by UV-visible spectral measurements with a VarianTechtron Super Scan 3 recording spectrophotometer and a Zeiss PMQ II spectrometer for measurements at single wavelengths. Changes of absorbance at selected wavelengths were used to calculate the amount of photolysis. At $380 \mathrm{~nm}$ the 
molar extinction coefficients are $\varepsilon=1240$ for $\left[\mathrm{Os}(\mathrm{CPh})(\mathrm{CO})_{2}\left(\mathrm{PPh}_{3}\right)_{2}\right]^{+}$and $\varepsilon=6460$ for $\mathrm{Os}(\mathrm{CHPh})(\mathrm{CO})\left(\mathrm{PPh}_{3}\right)_{2} \mathrm{Cl}_{2}$ in mixtures of $\mathrm{CH}_{2} \mathrm{Cl}_{2}$, ethanol, and aqueous $\mathrm{HCl}$. The extinction coefficient of $\mathrm{Os}(\mathrm{CHPh})(\mathrm{CO})\left(\mathrm{PPh}_{3}\right)_{2} \mathrm{Cl}_{2}$ was $\varepsilon=280$ at $535 \mathrm{~nm}$ in benzene. The neutral carbyne complex

$\mathrm{Os}(\mathrm{CPh})(\mathrm{CO})\left(\mathrm{PPh}_{3}\right)_{2} \mathrm{Cl}$ does not absorb at this wavelength.

\section{Results}

When solutions of $\mathrm{Os}(\mathrm{CPh})(\mathrm{CO})\left(\mathrm{PPh}_{3}\right)_{2} \mathrm{Cl}(\mathrm{I})$ in benzene were saturated with gaseous $\mathrm{HCl}$ the complex I was converted to $\mathrm{Os}(\mathrm{CHPh})(\mathrm{CO})\left(\mathrm{PPh}_{3}\right)_{2} \mathrm{Cl}_{2}$ (II) in a thermal reaction [11]. At low concentrations of $\mathrm{HCl}\left(\mathrm{c}<10^{-4} \mathrm{M}\right)$ this conversion was slow but could be accelerated by irradiation $(\lambda>320$ $\mathrm{nm})$. The photolysis was a smooth reaction as indicated by the spectral changes (Fig. 1). After longer irradiation times I was almost completely converted to II $\left(\lambda_{\max }=376 \mathrm{~nm}, \varepsilon=9800\right)$. The spectrum $f$ of Fig. 1 corresponds to a conversion of about $95 \%$. In benzene solutions containing $5 \times 10^{-5} \mathrm{M} \mathrm{HCl}$ the photolysis proceeds with a quantum yield of approximately $\varphi=0.1\left(\lambda_{\mathrm{irr}}=\right.$ $365 \mathrm{~nm}$ ). A precise determination was not possible due to the interference of the thermal reaction.

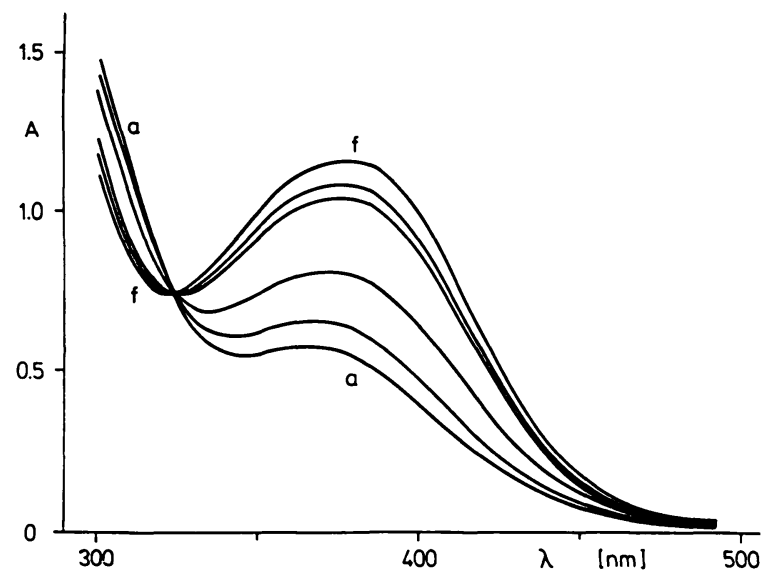

Fig. 1. Spectral changes during the irradiation of $4 \times 10^{-4} \mathrm{M} \mathrm{I}$ in benzene solutions containing $\mathrm{HCl}$ $\left(\sim 10^{-4} \mathrm{M}\right.$ ) at (a) 0 and (f) $30 \mathrm{~min}$ irradiation time, $\lambda_{\text {irr }}=366 \mathrm{~nm}$, and $1 \mathrm{~cm}$ cell.

The cation $\left[\mathrm{Os}(\mathrm{CPh})(\mathrm{CO})_{2}\left(\mathrm{PPh}_{3}\right)_{2}\right]^{+}$(III) did not react thermally in mixtures of $\mathrm{CH}_{2} \mathrm{Cl}_{2}$, ethanol, and hydrochloric acid $\left(\mathrm{c}<10^{-3} \mathrm{M} \mathrm{HCl}\right)$. However, upon irradiation $(\lambda>305 \mathrm{~nm})$ III underwent a photolysis. The accompanying spectral changes are shown in Fig. 2. At the beginning the photolysis was a smooth reaction as indicated by an isosbestic point at $344 \mathrm{~nm}$. The first photoproduct was identified as II by its absorption spectrum $\left(\lambda_{\max }=365 \mathrm{~nm}\right.$, $\varepsilon=7000$ in solutions of $\mathrm{CH}_{2} \mathrm{Cl}_{2}, \mathrm{C}_{2} \mathrm{H}_{5} \mathrm{OH}$, and aqueous $\mathrm{HCl})$. At the isosbestic point II and III have the same extinction coefficient $(\lambda=344 \mathrm{~nm}$, $\varepsilon=6800$ ). In this solvent II was apparently light sensitive and underwent a secondary photolysis. After continued irradiation the isosbestic point at $344 \mathrm{~nm}$ disappeared. It is assumed that II was photodecomposed since a decrease of extinction was observed over a large wavelength region $(\lambda>300 \mathrm{~nm})$. The primary photochemical reaction, the conversion of III to II, proceeds with a quantum yield of $\varphi=0.2\left(\lambda_{\mathrm{irr}}=313 \mathrm{~nm}, 10^{-3} \mathrm{M} \mathrm{HCl}\right)$ upon irradiation of the absorption band in the near UV.

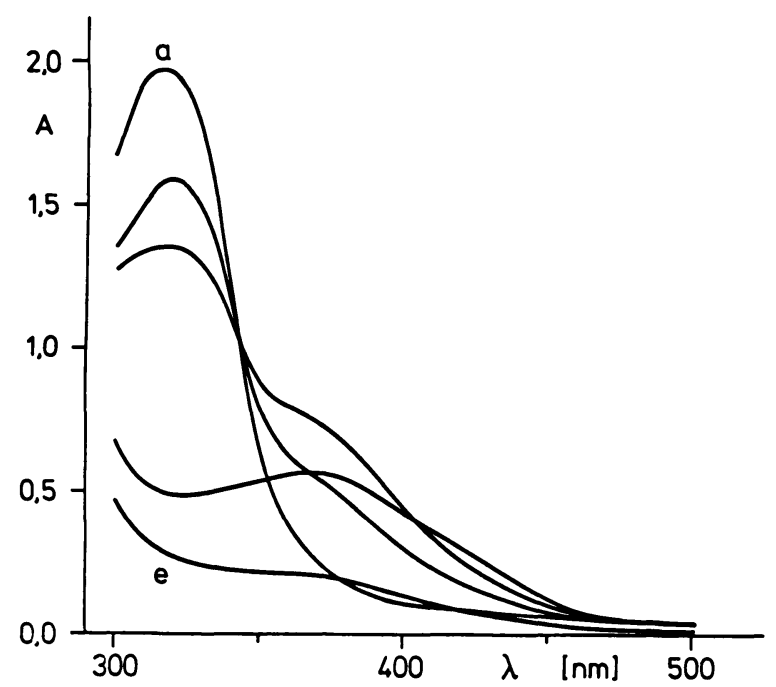

Fig. 2. Spectral changes during the irradiation of $1.3 \times 10^{-4} \mathrm{M}$ III in mixture of $\mathrm{CH}_{2} \mathrm{Cl}_{2}, \mathrm{C}_{2} \mathrm{H}_{5} \mathrm{OH}$, and aqueous $\mathrm{HCl}\left(6 \times 10^{-4} \mathrm{M} \mathrm{HCl}\right)$ at (a) 0 and $(\theta) 60 \mathrm{~min}$ irradiation time, $\lambda_{\mathrm{irr}}>305 \mathrm{~nm}$, and $1 \mathrm{~cm}$ cell.

\section{Discussion}

The electronic absorption spectra of the carbyne complexes I (Fig. 1) and III (Fig. 2) exhibit fairly intense long-wavelength absorption maxima at $318(\varepsilon=13500)$ and $366 \mathrm{~nm}(\varepsilon=4700)$ which we assign to charge transfer metal to ligand (CTML) transitions from osmium to the carbyne ligand. This assignment is based on several considerations. A trigonal-bipyramidal structure of I was confirmed 
by X-ray analysis [11]. The cation III has probably the same structure which is characteristic of many low-valent metal complexes with a $\mathrm{d}^{8}$ electron configuration. This requires formally as $\operatorname{Os}(0)$ metal center and a carbyne cation IC- $\mathrm{Ph}^{+}$as a ligand. Carbyne cations seem to be among the best $\pi$-acid ligands due to their energetically rather low-lying empty $\pi^{*}$ orbitals which can accept a large portion of charge by the interaction with occupied $d \pi$ orbitals of the metal [5-7]. The empty $\pi^{*}$-orbitals which are formed by the antibonding interaction may be localized to large extent at the carbyne ligand. A calculation on $\left[\mathrm{Fe}(\mathrm{CPh})(\mathrm{CO})_{2}\left(\mathrm{PH}_{3}\right)_{2}\right]^{+}$ which may be used as a model for III has shown [7], that the LUMO is indeed localized on the carbyne ligand to a large degree $(63 \%)$. In analogy to many other carbyne complexes the HOMO of III is assumed to be essentially a metal d-orbital. Consequently, it is quite reasonable to assign the low-energy absorption band of the cation III to the CTML (Os to carbyne) transition. The longwavelength absorption of the neutral complex I may be of the same origin. The photochemical results are also consistent with these assignments.

With regard to the photochemistry we suggest that the carbyne ligand has much in common with the nitrosyl ligand. Both cations, $\mathrm{CR}^{+}$[5-7] and $\mathrm{NO}^{+}[12]$ are very good $\pi$-acceptor ligands due to their low-energy empty $\pi^{*}$-orbitals. On the basis of this similarity we adopt an approach introduced by W. Evans and J. I. Zink for the interpretation of the photochemistry of nitrosyl complexes [13]. If we neglect the non-equivalence of the other four ligands of I and III we can apply the qualitative MO model developed by Enemark and Feltham for trigonal-bipyramidal complexes with a linear NO ligand (or carbyne ligand in our case) in an equatorial position [12]. In this $\mathrm{C}_{2 \mathrm{v}}$ symmetry the HOMO $\left(4 a_{1}\right)$ is derived from the $d_{z 2}$-orbital while the $\pi^{*}$-orbitals of NO (or the carbyne) contribute to the antibonding LUMO $\left(3 b_{1}\right)$ to a large degree. The $4 a_{1}$ to $3 b_{1}$ CTML (Os to carbyne) transition terminates in an excited state which may undergo considerable structural rearrangement. According to Enemark and Feltham a shift of electron density from the metal to the ligand will change the geometry from trigonal-bipyramidal to squarepyramidal with a bent NO (or carbyne) ligand in an axial position. This rearrangement decreases the energy of the antibonding $\pi^{*}$-orbitals of NO or the carbyne ligand and thus stabilizes the CT excited state. In a limiting description the CT transition induces a two-electron transfer from $\mathrm{Os}(0)$ to the carbyne ligand. As a result a square-pyramidal Os(II) complex is obtained with a bent carbyne in an axial position. The bent carbyne ligand carries now a lone pair at the coordinating carbon atom.

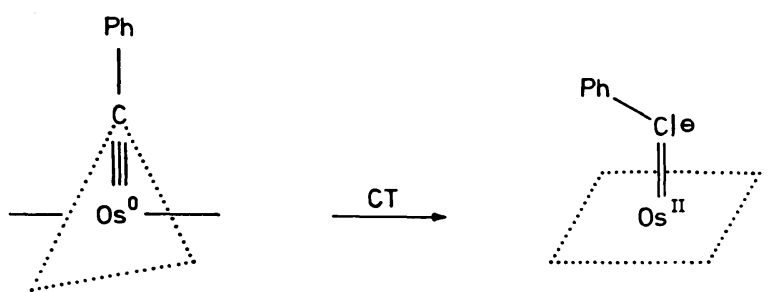

In another description the relaxed CT state could be envisaged as a coordinatively unsaturated octahedral Os(II) complex containing a deprotonated phenyl carbene ligand. In this situation the complex can be easily attacked by electrophiles such as a proton to generate a carbene ligand. At the same time a sixth ligand such as chloride should be attached to the metal to complete the octahedral coordination. Hydrochloric acid provides both functions. It adds apparently to the CT excited state of I or III to form the photoproducts II or $\left[\mathrm{Os}(\mathrm{CHPh})(\mathrm{CO})_{2}\left(\mathrm{PPh}_{3}\right)_{2} \mathrm{Cl}\right]+(\mathrm{IV})$.
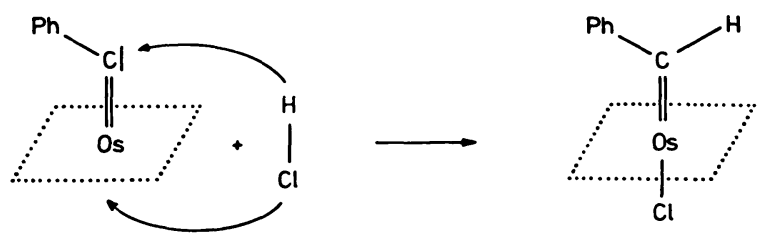

The cation IV is apparently not stable but undergoes a substitution of $\mathrm{CO}$ by chloride to yield II in a subsequent thermal reaction.

Even the addition of $\mathrm{HCl}$ to $\mathrm{I}$ in the thermal reaction may be explained by the Enemark-Feltham model [12]. If $\mathrm{Cl}^{-}$interacts with the carbyne complex in the ground state it could distort the trigonal-bipyramidal structure in direction to an octahedral geometry. This in turn should induce a transfer of two electrons from $O s(0)$ to the carbyne which then bends. A stabilization occurs by the addition of a proton to the lone pair of the 
bent carbyne ligand leading to an octahedral carbene complex. In the cation III the $4 a_{1}$-orbital is apparently much more stable [12]. Consequently, III will be more resistant towards the thermal addition of $\mathrm{HCl}$. In this context it is of interest that the five-coordinate complex $\left[\mathrm{CoNO}(\text { das })_{2}\right]^{2+}$ with das $=o$-phenylene-bis(dimethylarsine) easily adds a halide ion as sixth ligand to yield a stable octahedral complex $\left[\mathrm{CoNO}(\text { das })_{2} \mathrm{X}\right]^{+}$. This structural change is accompanied by a bending of the nitrosyl ligand $[12,13]$.

Financial support for this research by the Deutsche Forschungsgemeinschaft and the Fonds der Chemischen Industrie is gratefully acknowledged. We are grateful to Dr. A. H. Wright for assistance in the preparation of the carbyne complexes.
[1] E. O. Fischer, G. Kreis, C. G. Kreiter, J. Müller, G. Huttner, and H. Lorenz, Angew. Chem. 85, 618 (1973); Angew. Chem. Int. Ed. Engl. 12, 564 (1973).

[2] a) E. O. Fischer, U. Schubert, and H. Fischer, Pure Appl. Chem. 50, 857 (1978);

b) E. O. Fischer and U. Schubert, J. Organomet. Chem. 100, 59 (1975);

c) E. O. Fischer, Adv. Organomet. Chem. 14, 1 (1976).

[3] For recent references on carbyne complexes see ref. [4] and [5].

[4] a) A. Filippou and E. O. Fischer, Z. Naturforsch. 38 b, 587 (1983)

b) E. O. Fischer, P. Friedrich, T. L. Lindner, D. Neugebauer, F. R. Kreissl, and W. Uedelhoven, J. Organomet. Chem. 247, 239 (1983).

[5] N. M. Kostic and R. F. Fenske, J. Am. Chem. Soc. 103, 4677 (1981).
[6] N. M. Kostic and R. F. Fenske, Organometallics 1, 489 (1982).

[7] N. M. Kostic and R. F. Fenske, J. Am. Chem. Soc. 104, 3879 (1982).

[8] E. O. Fischer and P. Friedrich, Angew. Chem. 91, 345 (1979); Angew. Chem. Int. Ed. Engl. 18, 327 (1979).

[9] R. E. Wright and A. Vogler, J. Organomet. 160, 197 (1978).

[10] W. R. Roper, J. M. Waters, L. J. Wright, and F. van Meurs, J. Organomet. Chem. 201, C 27 (1980).

[11] G. R. Clark, K. Marsden, W. R. Roper, and L. J. Wright, J. Am. Chem. Soc. 102, 6570 (1980).

[12] J. H. Enemark and R. D. Feltham, Coord. Chem. Rev. 13, 339 (1974).

[13] W. Evans and J. I. Zink, J. Am. Chem. Soc. 103, 2635 (1981).

[14] R. D. Feltham and R. S. Nyholm, Inorg. Chem. 4, 1334 (1965). 